\title{
Inhibitory effect of Hsp70 on angiotensin II-induced vascular smooth muscle cell hypertrophy
}

\author{
Ying Zheng ${ }^{1,2}$, Chang-Nim $\mathrm{Im}^{1,2}$ and \\ Jeong-Sun Seo ${ }^{1,2,3}$ \\ ${ }^{1}$ ILCHUN Molecular Medicine Institute \\ ${ }^{2}$ Department of Biochemistry and Molecular Biology \\ Seoul National University College of Medicine \\ Seoul 110-799, Korea \\ ${ }^{3}$ Corresponding author: Tel, 82-2-740-8246; \\ Fax, 82-2-741-5423; E-mail, jeongsun@snu.ac.kr
}

Accepted 25 July 2006

Abbreviations: Ang II, angiotensin II; ERK, extracellular signalregulated kinase; Hsp70, heat shock protein 70; JNK, c-Jun N-terminal kinase; MAPK, mitogen-activated protein kinase; MEK1/2, MAPK kinase/ERK kinase 1/2; MKP, MAP kinase phosphatase; SEK1/MKK4, stress activated ERK kinase/MAP Kinase kinase 4; VSMC, vascular smooth muscle cell

\begin{abstract}
Angiotensin II (Ang II), which is an important mediator of both vascular responsiveness and growth, has been shown to induce vascular smooth muscle cell (VSMC) hypertrophy via the activation of a complex series of intracellular signaling events. Heat shock protein 70 (Hsp70) has recently been shown to protect against Ang II-induced hypertension. In this study, we tested the hypothesis that Hsp70 can protect VSMC from Ang II-induced hypertrophy. We treated VSMCs with Ang II to induce hypertrophy and to activate MAPK signaling pathway. We observed that the augmentation of Hsp70 expression inhibited Ang II-stimulated VSMC hypertrophy. This inhibitory effect of Hsp70 appears to be partly due to extracellular signal-regulated kinase (ERK1/2) inactivation, which in turn, may possibly result from the accumulation of MAP kinase phosphatase-1 (MKP-1).
\end{abstract}

Keywords: angiotensin II; heat shock protein 70; hypertrophy; mitogen-activated protein kinases; muscle, smooth, vascular

\section{Introduction}

Angiotensin II (Ang II), the principal product of the renin-angiotensin system (Touyz and Berry, 2002), participates in the induction of endothelial dysfunction, vascular remodeling, and inflammation, in pathological conditions such as hypertension and atherosclerosis. These effects are transduced through the G-protein coupled angiotensin subtype 1 (AT-1) receptor. A substantial body of in vitro studies indicates that Ang II directly induces vascular smooth muscle cell (VSMC) hypertrophy through AT-1 receptor (Geisterfer et al., 1988).

Stimulation of AT1 receptor by Ang II causes activation of mitogen-activated protein kinases (MAPK) (Touyz and Schiffrin, 2000). MAPK family is known to be involved in the regulation of a variety of cellular processes, including cell growth, differentiation, development, and cell survival. Ang II appears to activate extracellular signal-regulated kinase 1/2 (ERK1/2) and c-Jun N-terminal kinase/ stress-activated protein kinase (JNK/SAPK), which are probably associated with the regulation of VSMC growth (Yoshizumi et al., 2002; Miura et al., 2004). Ang II also phosphorylates vascular p38 MAPK, which is crucial to inflammatory responses and apoptosis (Hommes et al., 2003). These signaling processes and associated cellular functions are crucial to the development of the vascular damage associated with cardiovascular diseases, including hypertension and atherosclerosis (Touyz and Schiffrin, 2000; Suzuki et al., 2004; Tojo et al., 2005). The activation of the MAPKs is triggered by MAPK kinase (MKK or MEK) via phosphorylation of serine/ threonine residues (Sugden and Bogoyevitch, 1995). MEK1/2 directly phosphorylates ERK1/2 proteins (Bueno and Molkentin, 2002), and the upstream kinases, SEK1/MKK4 and MKK7, have been identified as direct JNK/SAPK activators, operating in response to a variety of stimuli (Deacon and Blank, 1997; Foltz et al., 1998). MKK3 and MKK6 selectively activate p38-MAPK in different cell types, and exhibit isoform specificity (Sugden and Clerk, 1998).

However, inactivation of MAPKs is known to be induced by the MAPK phosphatase 1 (MKP-1)-induced dephosphorylation of both tyrosine and threonine residues on the MAPKs. Ang II may induce sustained MAPK activation via the inhibition of MKP-1, which indicates that MKP-1 is principally responsible for the inhibition of the MAPK signal (Duff et al., 1995; Fischer et al., 1998).

The heat shock protein 70 (Hsp70) family is the best characterized and the most highly induced heat shock protein family. In the cardiovascular system, 
Hsp70 can be induced by a variety of stresses, including heat shock, oxidative stress, and mechanical stress (Cornelussen et al., 2001; Lee and Seo, 2002; Kim et al., 2003; Heo et al., 2006). Hsp70 also appears to play a crucial role in the protection of cells from environmental stresses (Latchman, 2001). Hsp70 overexpression confers thermotolerance on cells and improves cell survival in the presence of noxious stimuli ( $\mathrm{Li}$ et al., 2000, Park et al., 2000). Interestingly, the expression level of Hsp70 has shown to be directly related to the degree of myocardial protection from ischemia in rat hearts and Hsp70-overexpressing transgenic mouse hearts (Hutter et al., 1994).

Despite recent advances in our understanding of the protective effects of Hsp70, no information is currently available regarding the effect of Hsp70 on VSMC hypertrophy. In the present study, we characterized the effect of Hsp70 on Ang II-induced VSMC hypertrophy, as well as the associated signaling mechanisms. Our results show that Hsp70 exerts inhibitory effect on VSMC hypertrophy via the inactivation of ERK1/2, which is activated by Ang II, and that the Hsp70-mediated stabilization of MKP-1 may be involved in this process.

\section{Materials and Methods}

\section{Materials}

Materials were obtained from the following suppliers: human Ang II and FITC-conjugated, anti-actin, $\alpha$ smooth muscle antibody were obtained from Sigma (St. Louis, MO); Hsp70 antibody and MKP-1 antibody were obtained from Santa Cruz Biotechnology (Santa Cruz, CA); phospho-ERK1/2 and ERK1/2 antibodies, phospho-MEK1/2 and MEK1/2 antibodies were obtained from Cell Signaling (Beverly, MA); $\mathrm{I}-\left[4,5-{ }^{3} \mathrm{H}\right]$ leucine was purchased from Amersham Biosciences (Buckinghamshire, UK); PD98059 was purchased from Calbiochem (San Diego, CA). All other chemicals were obtained from commercial sources and were of reagent grade.

\section{Culture of rat aortic smooth muscle cells}

Strains of VSMC were established from rat thoracic aorta (10-week-old male Sprague-Dawley rat) by enzymatic digestion as described previously (Zheng et al., 2004). Cultures were maintained in Dulbecco's modified Eagle medium (DMEM)/F12 containing $10 \%$ fetal bovine serum (FBS), $100 \mathrm{U} / \mathrm{ml}$ penicillin and $100 \mu \mathrm{g} / \mathrm{ml}$ streptomycin and identified by the presence of positive staining with anti-actin, $\alpha$-smooth muscle antibody. All VSMC cultures used in the experiments were between the 3rd and 10th pa- ssages. VSMCs were grown to $70-80 \%$ confluence and made quiescent by serum starvation with serum-free DMEM/F12 medium for $48 \mathrm{~h}$.

\section{Transient Hsp70 overexpression and Hsp70 siRNA transfection}

VSMCs at approximately $70-80 \%$ confluence were transfected with pCMV-Hsp70 (Park et al., 2001) or empty vector plasmid, using Lipofectamine ${ }^{\mathrm{TM}}$ plus reagents (Invitrogen, Carlsbad, CA), in accordance with the manufacturer's instructions. After transfection for $24 \mathrm{~h}$, serum-starved cells were either left untreated, or treated with $100 \mathrm{nM}$ Ang II.

Hsp70 siRNA and scrambled siRNA were designed and synthesized (Invitrogen) as follows (X74271). Hsp70 siRNA sequence: 5'-gtctgaacgtgctgcggatcatcaa-3'; Scrambled siRNA sequence: 5'-gtcgcaatcgtggcgactatgtcaa-3'. Quiescent VSMCs were transfected with Hsp70 siRNA or scrambled siRNA, using Lipofectamine 2000 reagent (Invitrogen) in accordance with the manufacturer's instructions. After transfection for $36 \mathrm{~h}$, the VSMCs, incubated with or without Ang II, were used in each experiment.

\section{Measurement of $\left[{ }^{3} \mathrm{H}\right]$ leucine incorporation and protein content}

To measure hypertrophy of VSMCs, cells were seeded on 6-well culture plates at a density of $1.5 \times 10^{5}$ cells/well. Cells at $70 \sim 80 \%$ confluence were subjected to heat shock $\left(42^{\circ} \mathrm{C}\right.$ for $30 \mathrm{~min}$, recovery $12 \mathrm{~h})$ or transfected with pCMV-Hsp70, and then stimulated for $24 \mathrm{~h}$ with $100 \mathrm{nM}$ Ang II. The cells were incubated with $1 \mu \mathrm{Ci} / \mathrm{ml}\left[{ }^{3} \mathrm{H}\right]$ leucine during the last $8 \mathrm{~h}$ of stimulation. After washing with ice-cold PBS, $\left[{ }^{3} \mathrm{H}\right]$ leucine incorporation was assessed as described previously (Zheng et al., 2004).

VSMCs were seeded on 6-well culture plates at a density of $1.5 \times 10^{5}$ cells/well, and grown to $70-80 \%$ confluence. Serum-starved VSMCs were subjected to heat shock $\left(42^{\circ} \mathrm{C}\right.$ for $30 \mathrm{~min}$, recovery $\left.12 \mathrm{~h}\right)$, and then stimulated with $100 \mathrm{nM}$ Ang II for $24 \mathrm{~h}$. The cells were then lysed and the protein contents were determined (BCA assay kit, Pierce, Rockford, IL) in accordance with the manufacturer's instructions. The absorbance was measured at a wavelength of $570 \mathrm{~nm}$.

\section{Western blot analysis}

Western blot analysis was performed as described previously (Lee et al., 2005a). Total cell lysates (30 $\mu \mathrm{g})$ were subjected to SDS-PAGE and electrotransferred to nitrocellulose membrane (Schleicher and Schuell, Dassel, Germany). After blocking with $1 \times$ 
TBS/T (20 mM Tris-HCl, pH 7.6; $137 \mathrm{mM} \mathrm{NaCl,} 25$ $\mathrm{mM} \mathrm{KCl}, 0.1 \%$ Tween-20) containing $5 \%(\mathrm{w} / \mathrm{v})$ non-fat dry milk, blots were incubated with specific antibodies. Then, the blots were incubated with horseradish peroxidase-conjugated secondary antibodies (Santa Cruz, CA) and immunoactivity was visualized using the enhanced chemiluminescence detection system (Pierce) in accordance with the manufacturer's instructions.

A

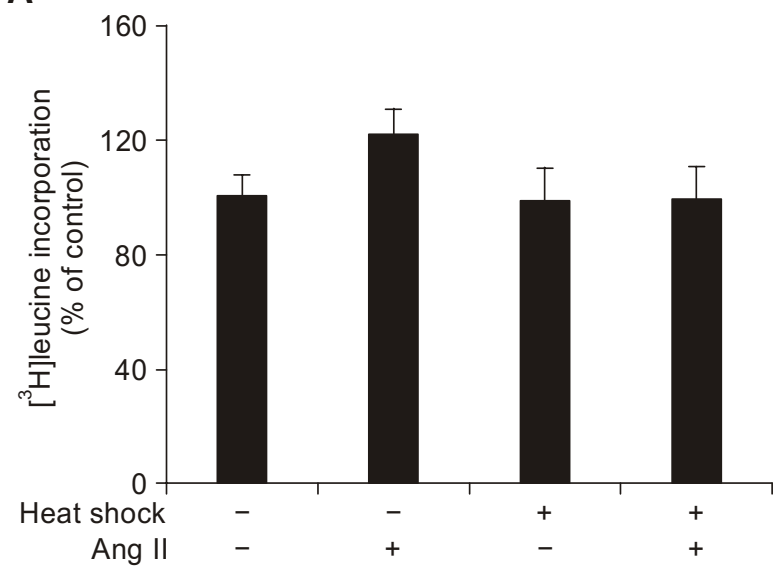

B

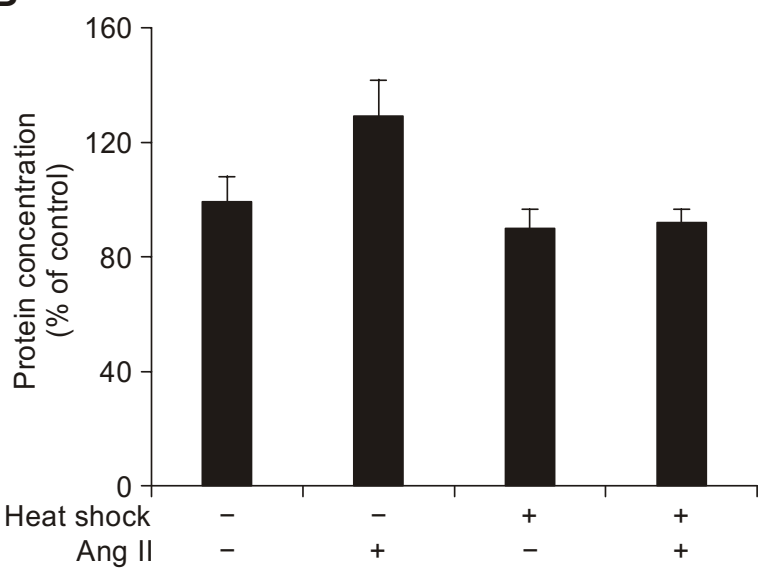

\section{Reverse transcriptase-PCR (RT-PCR)}

Total RNA was extracted from the VSMCs (TRIzol Reagent). $1 \mu \mathrm{g}$ of total RNA was reverse-transcribed using oligo (dT) primer (Invitrogen) and RT-PCR pre-mix (Bioneer corporation, Daejeon, Korea), and PCR was performed with this CDNA as a template using PCR pre-mix (GENENMED Inc.) in accordance with the manufacturer's instructions. 30 cycles were run, as follows: denaturation at $94^{\circ} \mathrm{C}$ for $30 \mathrm{~s}$, annealing at $57^{\circ} \mathrm{C}$ for $30 \mathrm{~s}$, and extension at $72^{\circ} \mathrm{C}$ for $30 \mathrm{~s}$. The following primers were used.

\section{C}
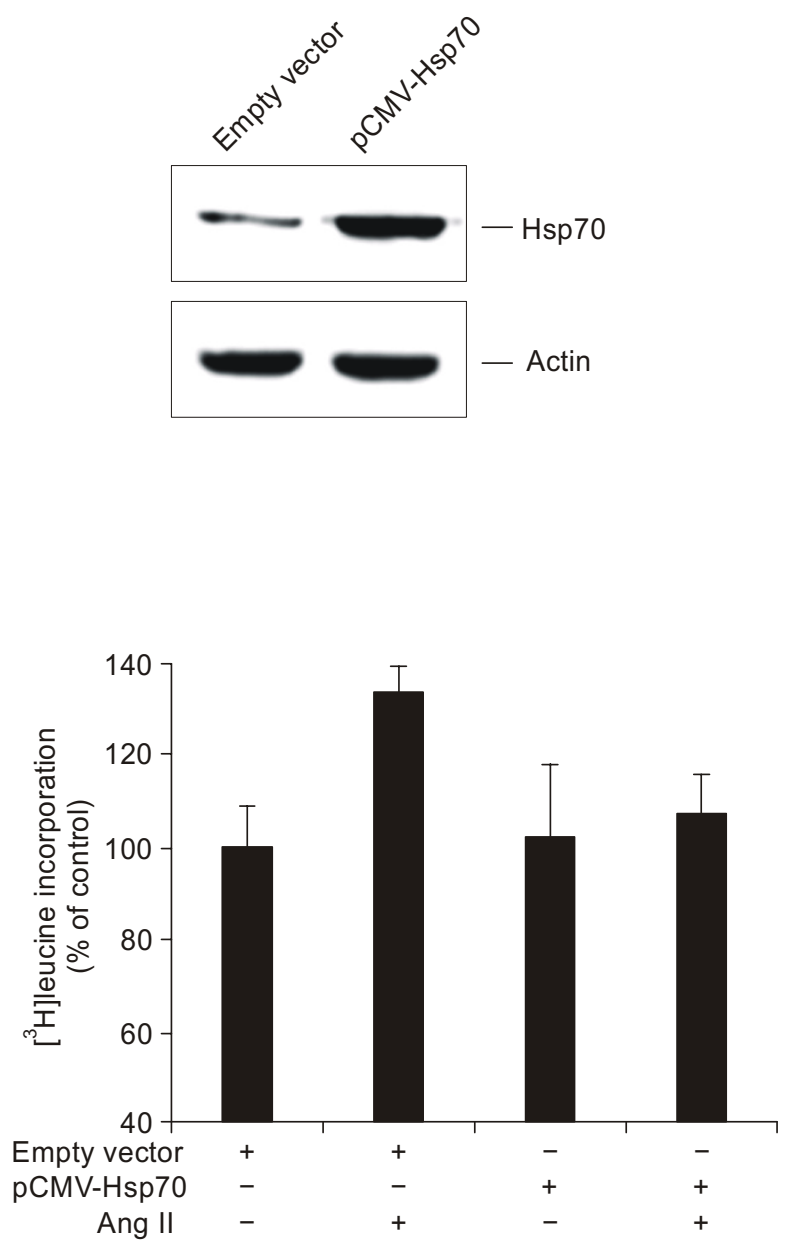

Figure 1. Inhibitory effect of Hsp70 on Ang II-induced VSMC hypertrophy. (A) Attenuation of Ang II-stimulated [ $\left.{ }^{3} \mathrm{H}\right]$ leucine incorporation by heat shock pre-treatment in VSMCs. Serum-starved VSMCs were treated with or without heat shock (at $42^{\circ} \mathrm{C}$ for $30 \mathrm{~min}$, and recovery $12 \mathrm{~h}$ ), then stimulated for $24 \mathrm{~h}$ with Ang II. VSMC hypertrophy was expressed as $\left[{ }^{3} \mathrm{H}\right]$ leucine incorporation. Three independent experiments were done and the data are expressed as means \pm SD. (B) Inhibitory effect of Hsp70 on Ang Il-induced protein synthesis. Serum-starved VSMCs were treated with or without heat shock (at $42^{\circ} \mathrm{C}$ for $30 \mathrm{~min}$, and recovery $12 \mathrm{~h}$ ), then stimulated for $24 \mathrm{~h}$ with Ang II. Protein contents were measured as described in Materials and Methods, and results were expressed as absorbance. Three independent experiments were done and the data are expressed as means \pm SD. (C) Attenuation of Ang II-stimulated [ $\left.{ }^{3} \mathrm{H}\right]$ leucine incorporation by overexpression of Hsp70 in VSMCs. Cells were transiently transfected with pCMV-Hsp70 or empty vector as described in Materials and Methods. The cells were then stimulated with or without $100 \mathrm{nM}$ Ang II for $24 \mathrm{~h}$. Overexpressed levels of Hsp70 in VSMCs were detected by immunoblotting (C, upper panel). VSMC hypertrophy was expressed as [ $\left.{ }^{3} \mathrm{H}\right]$ leucine incorporation (C, lower panel). Three independent experiments were done and the data are expressed as means \pm SD. 
Hsp70 (NM_031971): 5'-aacgtgctcatcttcgacct-3' sense; 5'-cgttggtgatggtgatcttg-3' antisense. MKP-1 (NM 053769): 5'-tctggattgtcgctccttct-3' sense; 5'-gtgatggggctttgaaggta-3' antisense. GAPDH (NM_017008): 5'-atgggaagctggtcatcaac-3' sense; 5'-ggatgcagggatgatgttct-3' antisense.

\section{Statistical analysis}

Results are expressed as means \pm S.D of three independent experiments. The statistical significance was assessed by paired or unpaired Student's $t$-test. A value of $P<0.05$ was considered to be statistically significant.

\section{Results}

\section{Hsp70 inhibits Ang II-induced VSMC hypertrophy}

The induction of Hsp70, in response to a host of potential stresses, has been correlated with enhanced stress resistance in many cell types, including VSMCs (Johnson et al., 1990; Xu and Wick, 1996; Gorostizaga et al., 2005). The stimulation of VSMC by Ang II has been shown to induce cellular hypertrophy (Geisterfer et al., 1988). Therefore, we attempted to determine the effect of Hsp70 on Ang II-induced $\left[{ }^{3} \mathrm{H}\right]$ leucine incorporation into the cells. The VSMCs were treated with heat shock prior to Ang II stimulation, and we observed that Ang II-stimulated $\left[{ }^{3} \mathrm{H}\right]$ leucine incorporation $(25.3 \%$ over that in control, $P<0.05$ ) was significantly inhibited by pre-treatment with heat shock $(P<0.05)$ (Figure
1A). Since cell hypertrophy involves increases in cellular protein contents, we evaluated the cellular protein contents stimulated by Ang II, in the presence or absence of heat shock treatment. Our results indicate that Ang II-induced increase in protein contents $(29.6 \%$ over that in control, $P<$ 0.01 ) was significantly inhibited by the administration of heat shock treatment $(P<0.05)$ (Figure 1B). The VSMCs were then transfected with either empty vector or pCMV-Hsp70 prior to Ang II stimulation, and the level of overexpression was determined by Western blot analysis (Figure 1C, upper panel). In the VSMCs transfected with empty vector, stimulation with $100 \mathrm{nM}$ Ang II for $24 \mathrm{~h}$ induced significant increase in $\left[^{3} \mathrm{H}\right]$ leucine incorporation $(34.2 \%$ over that in control, $P<0.01$ ). However, there was a significant attenuation of Ang II-stimulated $\left[{ }^{3} \mathrm{H}\right]$ leucine incorporation in the VSMCs overexpressing pCMV-Hsp70 $(P<0.01)$ (Figure 1C, lower panel). These results indicate that pre-induction of Hsp70 inhibits Ang II-induced VSMC hypertrophy.

\section{Effect of PD98059, a specific inhibitor of ERK1/2, on Ang II-stimulated VSMC hypertrophy}

We confirmed the relative contribution of ERK1/2 pathway to Ang II-mediated VSMC hypertrophy using PD98059, a pharmacological inhibitor of MEK. As seen in Figure 2A, Ang II (100 nM) caused a significant increase $(92.3 \%$ over that in control, $P<$ $0.01)$ in $\left[{ }^{3} \mathrm{H}\right]$ leucine incorporation into total protein. Pretreatment with PD98059 (25 to $50 \mu \mathrm{M} ; 30 \mathrm{~min}$ ) resulted in a dose-dependent decrease in Ang
A

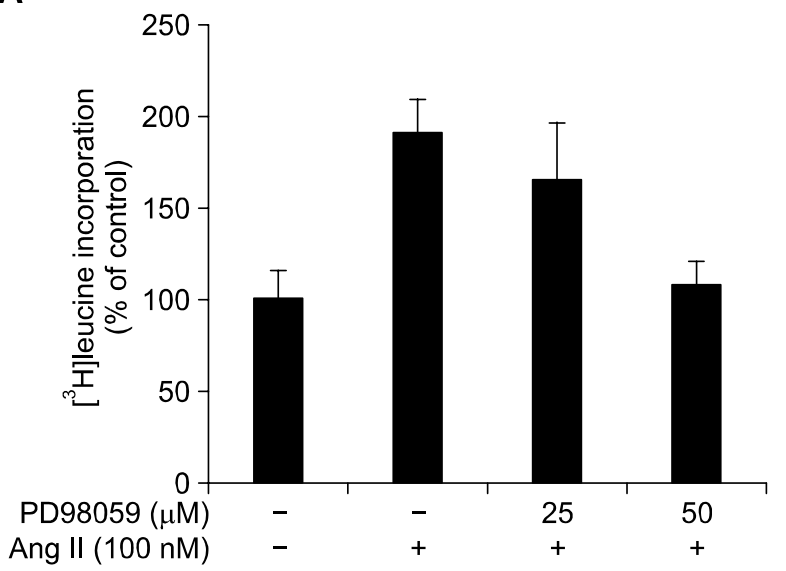

B

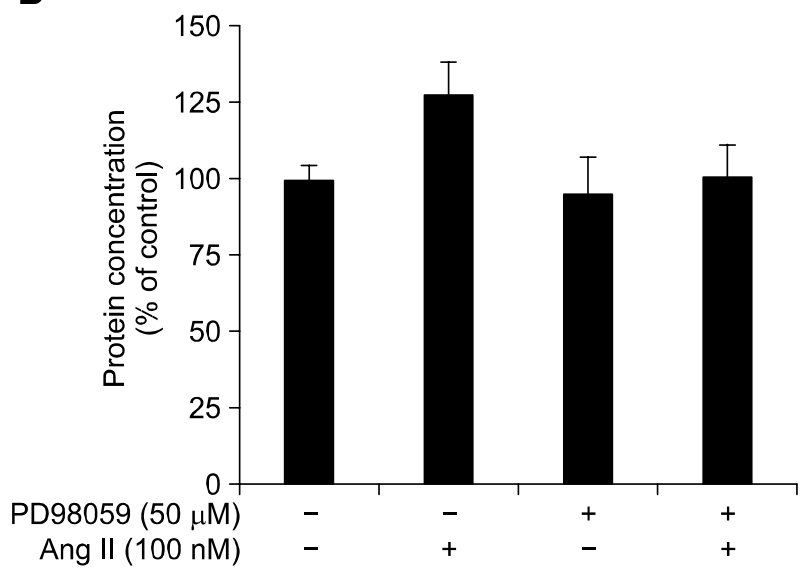

Figure 2. Effect of PD98059 on Ang II-stimulated VSMC hypertrophy. (A) Attenuation of Ang II-stimulated [ $\left.{ }^{3} \mathrm{H}\right]$ leucine incorporation by PD98059 in VSMCs. Serum-starved VSMCs were pretreated with PD98059 (25 to $50 \mu \mathrm{M})$ for 30 min and then stimulated with Ang II (100 nM) for $24 \mathrm{~h}$ with pulsed addition of $\left.{ }^{3} \mathrm{H}\right]$ leucine for the final $8 \mathrm{~h}$ as described under Materials and Methods. Values are expressed as means \pm SD from three different experiments. (B) Inhibitory effect of PD98059 on Ang II-increased protein contents. Serum-starved VSMCs were pretreated with PD98059 (50 $\mu$ M) for $30 \mathrm{~min}$ and then stimulated with Ang II (100 nM) for $24 \mathrm{~h}$. Protein contents were measured as described in Materials and Methods, and the data are expressed as means \pm SD from three independent experiments. 
A

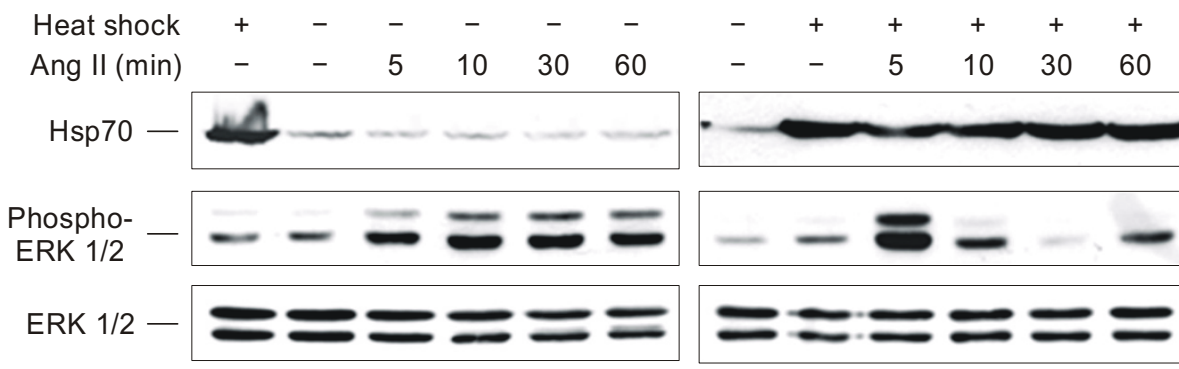

B

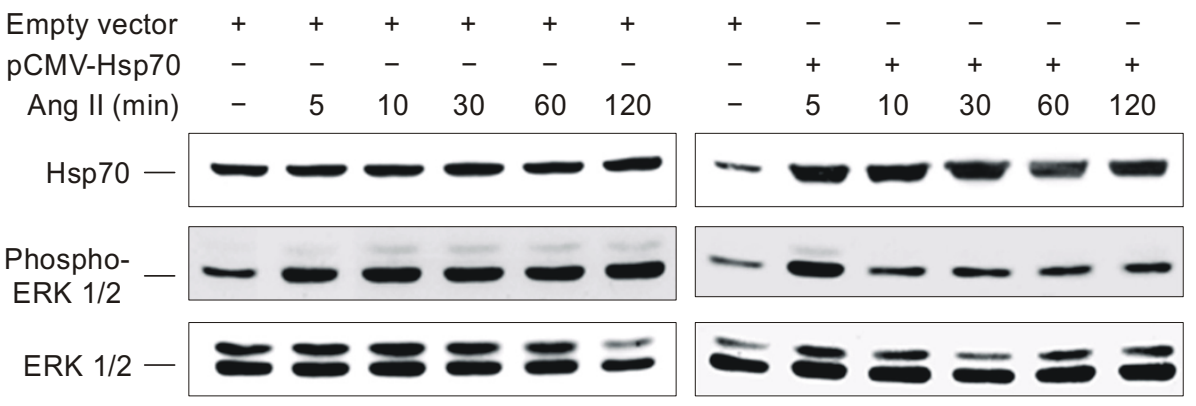

Figure 3. Effect of Hsp70 on ERK $1 / 2$ activation in Ang II-stimulated VSMCs. (A) VSMCs were treated with or without heat shock (at $42^{\circ} \mathrm{C}$ for $30 \mathrm{~min}$, and $12 \mathrm{~h}$ of recovery). (B) VSMCs were transiently transfected with pCMV-Hsp70 or empty vector, as described in Materials and Methods. The cells were then stimulated with $100 \mathrm{nM}$ Ang II for the indicated periods. Immunoblotting was conducted with the cell lysates. The detection of phospho-ERK1/2, total ERK1/2 and Hsp70 levels was accomplished using anti-phospho ERK1/2, anti-ERK1/2 and anti-Hsp70 antibodies, respectively. Representative blots of three individual experiments were shown.

II-dependent $\left[{ }^{3} \mathrm{H}\right]$ leucine incorporation, with a dramatic reduction $(P<0.01)$ in protein synthesis at the $50 \mu \mathrm{M}$ concentration.

We then evaluated the cellular protein contents increased by Ang II, in the presence or absence of PD98059 pre-treatment. Our results indicate that Ang II-induced increase in protein contents $(27.9 \%$ over that in control, $P<0.01)$ was significantly inhibited by the pre-treatment of PD98059 $(50 \mu \mathrm{M}$; $30 \mathrm{~min})(P<0.01)$ (Figure 2B). These results suggest that the ability of Ang II to increase protein synthesis was reduced by ERK $1 / 2$ inhibition, which indicates the involvement of ERK1/2 in Ang II-stimulated VSMC hypertrophy.

\section{Inhibitory effect of Hsp70 on Ang Il-induced ERK1/2 activation}

It is known that MAPK pathway is activated by Ang II and is required for Ang II-induced VSMC hypertrophy (Govindarajan et al., 2000; Touyz and Berry, 2002). Thereafter, in order to identify a possible role for Hsp70 in the regulation of intracellular signaling cascades, we first attempted to determine whether Hsp70 might modulate the Ang II-induced activation of MAPKs. Hsp70 was induced in the VSMCs by exposing the cells to heat shock, or via transient overexpression of pCMV-Hsp70, followed by treatment with Angll. In both the heat shock- treated cells and the pCMV-Hsp70 overexpressing cells, Ang II-induced activation of ERK $1 / 2$ was inhibited dramatically after 10 minutes. (Figure $3 \mathrm{~A}$ and $3 \mathrm{~B}$ ).

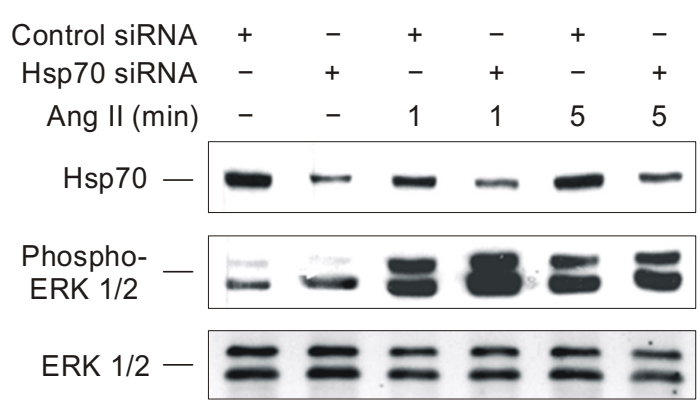

Figure 4. Effect of Hsp70 siRNA on ERK 1/2 activation in Ang II-stimulated VSMCs. VSMCs were transiently transfected with Hsp70 siRNA or scrambled siRNA, as described in Materials and Methods. The cells were then stimulated with $100 \mathrm{nM}$ Ang II for the indicated periods. Immunoblotting was conducted with the cell lysates. Levels of Hsp70 expression, ERK1/2 phosphorylation and total ERK1/2 expression were detected with anti-Hsp70, anti-phospho ERK1/2 and anti-ERK1/2 antibodies, respectively. Representative blots of three individual experiments were shown.

No significant differences in ERK1/2 activity were observed between the Hsp70 overexpressed cells and the empty vector transfected cells in the absence of Ang II treatment (data not shown). The induction of $\mathrm{Hsp} 70$ had no effect on intracellular levels of endogenous ERK1/2 protein in either the heat shock-treated or transfected VSMCs. JNK/ SAPK and p38 MAPK activities were also analyzed via the same technique and the results indicated that Hsp70 exerted no such inhibitory effect on Ang II-stimulated JNK/SAPK and p38 MAPK activity 
(data not shown). Collectively, these findings suggest that Hsp70 specifically inhibits Ang II-stimulated activation of ERK1/2 in VSMCs.

\section{Effect of Hsp70 siRNA on Ang II-induced ERK1/2 activation}

We confirmed the effect of Hsp70 on Ang II-stimulated ERK1/2 activation, using Hsp70 siRNA. The quiescent VSMCs were transfected with Hsp70 siRNA or scrambled siRNA, and then treated with or without $100 \mathrm{nM}$ Ang II. Western blot analysis indicated that the activity of ERK1/2 was slightly increased in the cells transfected with Hsp70 siRNA compared to the scrambled siRNA transfected cells with 0-1 min of Ang II treatment. However, in cases in which the Ang II treatment was sustained for more than 5 min, we observed that Hsp70 siRNA just prevented the inhibition of ERK1/2 activity (Figure 4). The reduced Hsp70 expression levels had no effect on the intracellular levels of endogenous ERK1/2 proteins in Hsp70 siRNA transfected VSMCs. These results suggest that downregulation of Hsp70 expression by Hsp70 siRNA may prevent the inhibitory effect of Hsp70 on Ang II-stimulated ERK1/2 activation.

\section{Hsp70 has no effect on MEK1/2 activity}

The induction of ERK1/2 activation typically involves phosphorylation by a MAPK kinase, also known as
MEK1/2. In order to characterize the mechanism underlying the inhibition of ERK $1 / 2$ activity by $\mathrm{Hsp} 70$, we evaluated the effect of Hsp70 on Ang II-stimulated activation of MEK1/2. VSMCs were treated with heat shock or overexpressed with pCMV-Hsp70 prior to the addition of Ang II (100 nM). In the cells whether or not exposed to heat shock treatment, MEK1/2 was activated by Ang II stimulation for 1-5 min, and the activity decreased rapidly after stimulation for $10 \mathrm{~min}$ (Figure 5A). Moreover, in the cells transfected with the empty vector, or transfected with pCMV-Hsp70, MEK1/2 activation was also stimulated by Ang II, and the activation pattern was similar to that of the cells exposed to heat shock treatment (Figure 5B). These findings suggest that the inhibition of ERK1/2 by Hsp70 does not occur via inhibition of the upstream kinase MEK1/2. Therefore, the inhibition of ERK1/2 by Hsp70 may occur via an increase in the inactivation of this kinase in the VSMCs.

\section{Relationship between MKP-1 stabilization by Hsp70} and Ang Il-induced MKP-1 expression in VSMCs Heat shock treatment was reported to increase the protein and mRNA levels of MKP-1, which might contribute to the inactivation of MAPKs after the administration of heat shock (Gorostizaga et al., 2005). In order to confirm the expression of MKP-1 in conjunction with heat shock, the expression of MKP-1 mRNA was studied by RT-PCR. Our results
A

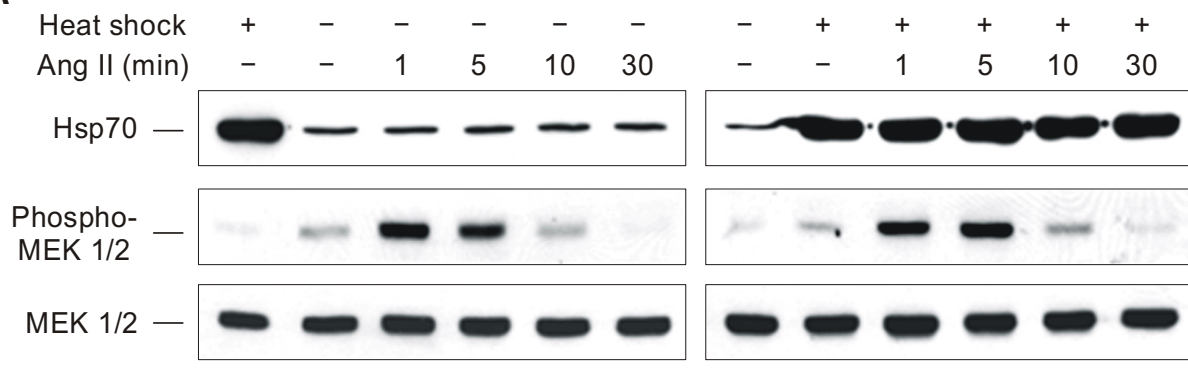

B

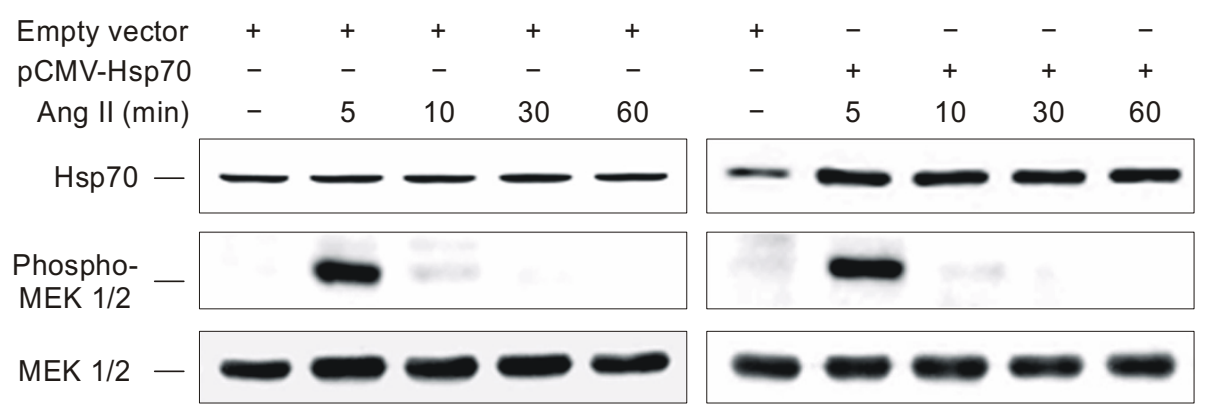

Figure 5. Effect of Hsp70 on MEK1/2 activation in Ang II-stimulated VSMCs. (A) VSMCs were treated with heat shock (at $42^{\circ} \mathrm{C}$ for $30 \mathrm{~min}$, and $12 \mathrm{~h}$ of recovery) or left untreated. (B) VSMCs were transiently transfected with $\mathrm{pCMV}$ Hsp70 or empty vector, as described in Materials and Methods. The cells were then stimulated with $100 \mathrm{nM}$ Ang II for the indicated periods. Immunoblotting was conducted with the cell lysates. Phospho-MEK1/2 and total MEK1/2 were detected using anti-phospho MEK1/2 and anti-MEK1/2 antibodies, respectively. Representative blots of three individual experiments were shown. 
A

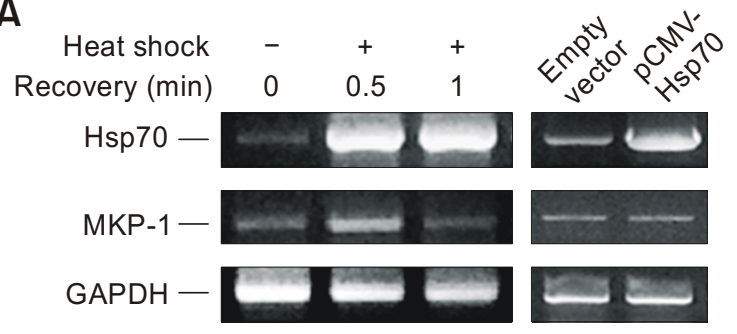

B

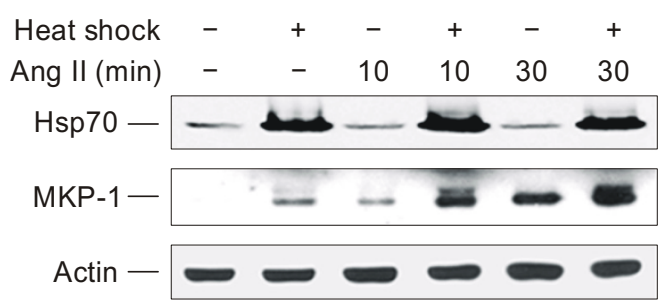

C

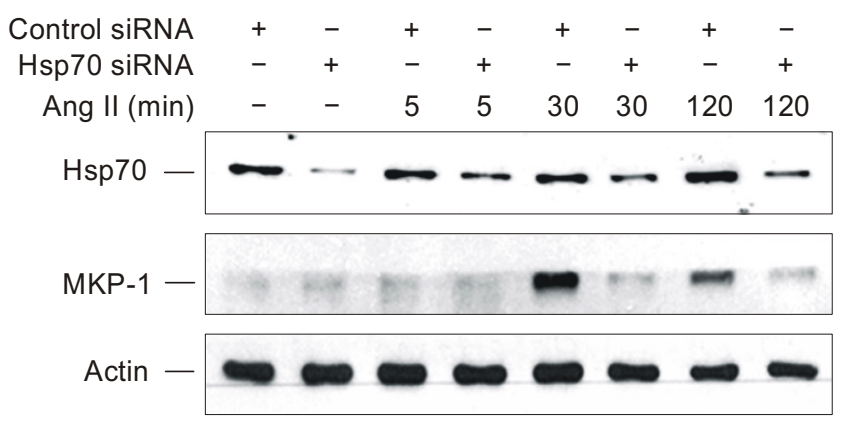

Figure 6. Effect of heat shock or Hsp70 siRNA on Ang II-induced MKP-1 expression. (A, left) VSMCs were exposed to heat shock for 30 min at $42^{\circ} \mathrm{C}$, and then allowed to recover for the indicated periods. RT-PCR was conducted as described in the Materials and Methods. (A, right) VSMCs were transiently transfected with pCMV-Hsp70 or empty vector, as described in Materials and Methods. Then, RT-PCR was conducted as described in the Materials and Methods. (B) VSMCs were treated with or without heat shock (at $42^{\circ} \mathrm{C}$ for $30 \mathrm{~min}$, and $12 \mathrm{~h}$ of recovery), after which the cells were stimulated with $100 \mathrm{nM}$ Ang II for the indicated periods. (C) VSMCs were transiently transfected with Hsp70 siRNA or scrambled siRNA, as described in Materials and Methods. The cells were then stimulated with Ang II for the indicated periods. Immunoblotting was conducted with the cell lysates. Hsp70 and MKP-1 expression were detected using anti-Hsp70 and anti-MKP-1 antibodies, respectively. Representative blots of three individual experiments were shown.

indicate that the expression of MKP-1 mRNA peaked at $30 \mathrm{~min}$ after recovery from heat shock, and that the expression pattern was similar to that of Hsp70 mRNA (Figure 6A, left). To determine whether Hsp70 can stimulate the transcription of MKP-1, VSMCs were overexpressed with pCMV-Hsp70, and then the expression of MKP-1 mRNA was studied by RT-PCR. In the cells transfected with the empty vector, or transfected with pCMV-Hsp70, MKP-1 mRNA level was similar to each other, and this suggests that $\mathrm{Hsp} 70$ does not directly stimulate the transcription of MKP-1 gene (Figure $6 \mathrm{~A}$, right). In order to determine the role of Hsp70 on Ang IIstimulated MKP-1 expression, Hsp70 was expressed at high levels by heat shock, and then stimulated with Ang II in VSMCs. Levels of Hsp70 and MKP-1 expression were analyzed by Western blotting. We found that Ang II induced a significant increase in the expression of MKP-1 after 30 min of treatment. However, the pre-induction of $\mathrm{Hsp} 70$ by heat shock resulted in accumulation of MKP-1 expression in the VSMCs, even in the absence of Ang II treatment. After Ang II stimulation, the levels of MKP-1 expression in the heat shock pre-treated cells were significantly higher than the levels of Ang II-induced MKP-1 expression seen in the absence of heat shock (Figure 6B).

In order to verify the effect of Hsp70 on Ang
II-stimulated MKP-1 expression, Hsp70 siRNA was employed to downregulate the expression of Hsp70. VSMCs were then treated with $100 \mathrm{nM}$ Ang II. The levels of Hsp70 and MKP-1 expression were analyzed by Western blotting. Our results indicate that Ang II-induced MKP-1 expression peaked at $30 \mathrm{~min}$. However, MKP-1 expression level was decreased dramatically in Hsp70 siRNA transfected VSMCs even after Ang II treatment for $2 \mathrm{~h}$ (Figure 6C). These results are consistent with those obtained after heat shock treatment. Collectively, these findings indicate that the Hsp70 stabilizes MKP-1 which can in turn dephosphorylate Ang II-activated ERK1/2 in VSMC.

\section{Discussion}

A variety of stress proteins, particularly Hsp70, seem to play protective roles in conditions such as hypertension and atherosclerosis (Johnson et al., 1990; Xu et al., 1995; Xu and Wick, 1996; Snoeckx et al., 2001). For example, heat shock treatment protects against Ang II-induced hypertension and inflammation (Chen et al., 2004), and administration of heat shock for $2 \mathrm{~h}$ at $43^{\circ} \mathrm{C}$ inhibits the proliferation of vascular smooth muscle cells (Orihara et al., 2002). However, to date, little is known about the role of 
Hsp70 on Ang II-induced VSMC hypertrophy. In the present study, we identified the effect of Hsp70 on VSMC hypertrophy and its role in the signaling pathways stimulated by Ang II. Numerous studies have shown that Ang II stimulates protein synthesis and cellular hypertrophy through AT-1 receptor in VSMCs, and may participate in the induction of pathological states associated with atherosclerosis and hypertension (Geisterfer et al., 1988; Touyz and Schiffrin, 2000). Increased $\left[{ }^{3} \mathrm{H}\right]$ leucine incorporation has been suggested to be involved in the increase of protein synthesis and resultant cellular hypertrophy caused by Ang II (Huwiler A, 1995). We first determined the effect of Hsp70 on the Ang II-induced increase in $\left[{ }^{3} \mathrm{H}\right]$ leucine incorporation into the cells. In addition, cellular protein content was measured to confirm the results from the measurement of $\left[{ }^{3} \mathrm{H}\right]$ leucine incorporation. As shown in Figure 1, Ang II caused an increase in $\left[{ }^{3} \mathrm{H}\right]$ leucine incorporation that was inhibited by prior heat shock-treatment and Hsp70-overexpression, which are consistent with the results from measurement of cellular protein contents. These results suggest that $\mathrm{Hsp} 70$ may have a specific anti-hypertrophic effect on Ang II-stimulated VSMC.

The MAPK cascade is an intracellular signaling module, and Ang II activates MAPK cascades in VSMC (Touyz and Berry, 2002), which is consistent with our results (data not shown). Since Ang II-induced MAPK activations have been implicated in the cellular hypertrophy in VSMC (Ushio-Fukai et al., 1998; Touyz and Schiffrin, 2000; Yoshizumi et al., 2002; Zheng et al., 2004), we examined the effect of Hsp70 on Ang II-induced MAP kinase activation in VSMC. First, we confirmed the involvement of ERK1/2 in Ang II-mediated VSMC hypertrophy using a specific inhibitor, PD98059 (Figure 2), which is consistent with the previous reports (Ushio-Fukai et al., 1998; Touyz et al., 1999; Govindarajan et al., 2000). We then examined the effect of Hsp70 on Ang II-induced ERK1/2 activation and observed for the first time that Hsp70 specifically inhibited Ang II-induced ERK1/2 activation in VSMC (Figure 3). In contrast to these results, downregulation of $\mathrm{Hsp} 70$ via transfection with Hsp70 siRNA prevented the inhibition of ERK1/2 activation, in VSMCs (Figure 4). These results are consistent with previous reports that preheating accelerates the inactivation of ERK1/2 (Lee et al., 2005b) and that a deficiency in Hsp70 induces activation of ERK1/2 in hyperosmolarity- induced apoptosis (Lee et al., 2005a). In addition, JNK/SAPK and p38 MAPK have also been proposed to be involved in Ang II-mediated VSMC hypertrophy (Ushio-Fukai et al., 1998; Yoshizumi et al., 2002). However, JNK/SAPK and p38 MAPK may not be involved in the inhibition of Hsp70 on VSMC hypertrophy by Ang II, because Hsp70 exerted no significant effect on Ang II-activiated JNK/SAPK and p38 MAPK (data not shown). Based on these findings, it may be reasonable to speculate that inhibition of Ang II-induced ERK1/2 activation by Hsp70 is attributable to the inhibition of activation by upstream kinases or to the increase of inactivation by specific phosphatases.

The MAPKs are a subset of serine/threonine kinases, which target substrates in a multilayered signaling network, composed of MAPKs, MAPK kinases (MKKs), and MEK kinases (MEKKs). In response to the activation of MAPKs, a family of dual-specificity phosphatases is transcriptionally induced, resulting in the specific dephosphorylation and inactivation of MAPKs (Haneda et al., 1999). MKP-1 is an important member of the dual-specificity phosphatase family, which regulates the inactivation of MAPKs. Reflecting the tight regulation of MAPK signaling, Ang II was shown not only to induce the activation of MAPKs, but also to be implicated in the up-regulation of MKP-1 (Sandberg et al., 2004). Recent studies have determined that MKP-1 is a heat shock responsive gene and that MKP-1 expression results from the combined effects of increases in both transcription and stability of MKP-1 (Wong et al., 2005). Another report (Lee et al., 2005b), suggests that heat shock-mediated increase in MKP-1 expression and Hsp70-induced early phosphorylation of MKP-1, are also associated with rapid inactivation of ERK1/2. Therefore, we examined whether Hsp70 inhibited ERK1/2 activation via the inhibition of upstream kinase, or via the acceleration of MAPK inactivation by MKP-1. We found that the pre-induction with $\mathrm{Hsp} 70$ resulted in no significant effect on the activity of MEK $1 / 2$, the upstream kinase of ERK1/2 (Figure 5). These results suggest that the inhibitory effect of Hsp70 on Ang II-activated ERK1/2 is independent of the upstream kinase, consistent with previous report (Lee et al., 2005b). However, interestingly, pre-induction with Hsp70 increased the accumulation of MKP-1 protein, much earlier and more severely than that seen with Ang II only (Figure 6B). We also determined that the downregulation of Hsp70 by Hsp70 siRNA dramatically decreased the accumulation of MKP-1 protein, whereas in the scrambled siRNA-transfected cells, Ang II induced a significant upshift in MKP-1 expression after only 30 min (Figure $6 C$ ). These results indicate that $\mathrm{Hsp} 70$ regulates MKP-1, which in turn promotes the inactivation of ERK1/2. Our study of whether MKP-1 expression is regulated by $\mathrm{Hsp} 70$ at transcriptional level or at posttranscriptional level showed that heat shock induced both Hsp70 and MKP-1 transcription in a similar time frame. Many heat shock proteins are regulated at the trans- 
criptional level and are dependent on the transcription factor, heat shock factor-1 (HSF-1), and heat shock elements (HSE) in the promoter regions of heat shock protein genes (Georgopoulos and Welch, 1993). Since MKP-1 promoter contains HSEs which appear to be important in the regulation of transcription in response to heat shock (Wong et al., 2005), it is reasonable that HSF and HSEs may be involved in the heat shock-stimulated MKP-1 transcription. However, Hsp70 overexpression by pCMV-Hsp70 did not affect MKP-1 mRNA expression (Figure 6A). This implies that heat shock may stimulate transcription of both $\mathrm{Hsp} 70$ and MKP-1, while Hsp70 may not be involved in the regulation of MKP-1 transcription. The mechanisms underlying the MKP-1 transcription by heat shock remain to be elucidated in VSMC. Considering these results and a recent study (Lee et al., 2005b), Hsp70 appears to be involved in MKP-1 stabilization potentially through post-transcriptional mechanism. Taken together, these results suggest that Hsp70 may accelerate the inactivation of Ang II-activated ERK1/2 through stabilization of MKP-1. However, the interaction between $\mathrm{Hsp} 70$ and MKP-1 remain to be elucidated in Ang II-stimulated VSMC.

In summary, this study shows that Hsp70 inhibits Ang II-induced VSMC hypertrophy through the inactivation of ERK1/2 through MKP-1 accumulation, and provides a rationale for the use of Hsp70 in the therapy of cardiovascular diseases.

\section{Acknowledgement}

These studies were funded by a grant from the Korea Transgenic Research Foundation (KTRF, 05-01) and in part by the 2005 BK21 project for Medicine, Dentistry and Pharmacy to Jeong-Sun Seo. We thank Sri Ram for a critical reading of the manuscript.

\section{References}

Bueno OF, Molkentin JD. Involvement of extracellular signalregulated kinases $1 / 2$ in cardiac hypertrophy and cell death. Circ Res 2002;91:776-81

Chen Y, Ross BM, Currie RW. Heat shock treatment protects against angiotensin II-induced hypertension and inflammation in aorta. Cell Stress Chaperones 2004;9:99-107

Cornelussen RN, van Nieuwenhoven FA, Snoeckx LH, Knowlton AA. Presence of heat shock protein 72 in cardiomyocytes after heat stress. Circulation 2001;104:E123

Deacon K, Blank JL. Characterization of the mitogen-activated protein kinase kinase 4 (MKK4)/c-Jun NH2-terminal kinase 1 and MKK3/p38 pathways regulated by MEK kinases 2 and 3 . MEK kinase 3 activates MKK3 but does not cause activation of p38 kinase in vivo. J Biol Chem 1997;272:14489-96
Duff JL, Monia BP, Berk BC. Mitogen-activated protein (MAP) kinase is regulated by the MAP kinase phosphatase (MKP-1) in vascular smooth muscle cells. Effect of actinomycin $D$ and antisense oligonucleotides. J Biol Chem 1995;270:7161-6

Fischer TA, Singh K, O'Hara DS, Kaye DM, Kelly RA. Role of AT1 and AT2 receptors in regulation of MAPKs and MKP-1 by ANG II in adult cardiac myocytes. Am J Physiol 1998;275: H906-H16

Foltz IN, Gerl RE, Wieler JS, Luckach M, Salmon RA, Schrader JW. Human mitogen-activated protein kinase kinase 7 (MKK7) is a highly conserved c-Jun N-terminal kinase/stress-activated protein kinase (JNK/SAPK) activated by environmental stresses and physiological stimuli. J Biol Chem 1998;273: 9344-51

Geisterfer AA, Peach MJ, Owens GK. Angiotensin II induces hypertrophy, not hyperplasia, of cultured rat aortic smooth muscle cells. Circ Res 1988;62:749-56

Georgopoulos C, Welch WJ. Role of the major heat shock proteins as molecular chaperones. Annu Rev Cell Biol 1993;9: 601-34

Gorostizaga A, Brion L, Maloberti P, Maciel FC, Podesta EJ, Paz C. Heat shock triggers MAPK activation and MKP-1 induction in Leydig testicular cells. Biochem Biophys Res Commun 2005;327:23-8

Govindarajan G, Eble DM, Lucchesi PA, Samarel AM. Focal adhesion kinase is involved in angiotensin II-mediated protein synthesis in cultured vascular smooth muscle cells. Circ Res 2000;87:710-6

Haneda M, Sugimoto T, Kikkawa R. Mitogen-activated protein kinase phosphatase: a negative regulator of the mitogenactivated protein kinase cascade. Eur J Pharmacol 1999;365: 1-7.

Heo JI, Lee MS, Kim JH, Lee JS, Kim J, Park JB, Lee JY, Han $\mathrm{JA}, \mathrm{Kim} \mathrm{JI}$. The role of tonicity responsive enhancer sites in the transcriptional regulation of human hsp70-2 in response to hypertonic stress. Exp Mol Med 2006;38:295-301

Hommes DW, Peppelenbosch MP, van Deventer SJ. Mitogen activated protein (MAP) kinase signal transduction pathways and novel anti-inflammatory targets. Gut 2003;52:144-51

Hutter MM, Sievers RE, Barbosa V, Wolfe CL. Heat-shock protein induction in rat hearts. A direct correlation between the amount of heat-shock protein induced and the degree of myocardial protection. Circulation 1994;89:355-60

Huwiler A, Stabel S, Fabbro D, Pfeilschifter J. Platelet-derived growth factor and angiotensin II stimulate the mitogenactivated protein kinase cascade in renal mesangial cells: comparison of hypertrophic and hyperplastic agonists. Biochem J 1995;305:777-84

Johnson AD, Berberian PA, Bond MG. Effect of heat shock proteins on survival of isolated aortic cells from normal and atherosclerotic cynomolgus macaques. Atherosclerosis 1990;84:111-9

Kim SH, Koh GY, Cho KW, Park WY, Seo JS. Stretch-activated atrial natriuretic peptide secretion in atria with heat shock protein 70 overexpression. Exp Biol Med (Maywood) 


\section{$2003 ; 228: 200-6$}

Latchman DS. Heat shock proteins and cardiac protection. Cardiovasc Res 2001;51:637-46.

Lee JS, Seo JS. Differential expression of two stress-inducible hsp70 genes by various stressors. Exp Mol Med 2002;34: 131-6

Lee JS, Lee JJ, Seo JS. HSP70 deficiency results in activation of c-Jun N-terminal Kinase, extracellular signal-regulated kinase, and caspase-3 in hyperosmolarity-induced apoptosis. J Biol Chem 2005a;280:6634-41

Lee KH, Lee CT, Kim YW, Han SK, Shim YS, Yoo CG. Preheating accelerates mitogen-activated protein (MAP) kinase inactivation post-heat shock via a heat shock protein 70-mediated increase in phosphorylated MAP kinase phosphatase-1. J Biol Chem 2005b;280:13179-86

Li CY, Lee JS, Ko YG, Kim JI, Seo JS. Heat shock protein 70 inhibits apoptosis downstream of cytochrome $c$ release and upstream of caspase-3 activation. J Biol Chem 2000;275: 25665-71

Miura S, Zhang J, Matsuo Y, Saku K, Karnik SS. Activation of extracellular signal-activated kinase by angiotensin II-induced Gq-independent epidermal growth factor receptor transactivation. Hypertens Res 2004;27:765-70

Orihara K, Biro S, Hamasaki S, Eto H, Miyata M, Ikeda Y, Tei C. Hyperthermia at 43 degrees $C$ for $2 h$ inhibits the proliferation of vascular smooth muscle cells, but not endothelial cells. J Mol Cell Cardiol 2002;34:1205-15

Park HS, Lee JS, Huh SH, Seo JS, Choi EJ. Hsp72 functions as a natural inhibitory protein of c-Jun $\mathrm{N}$-terminal kinase. EMBO J 2001;20:446-56

Park KC, Kim DS, Choi HO, Kim KH, Chung JH, Eun HC, Lee JS, Seo JS. Overexpression of HSP70 prevents ultraviolet B-induced apoptosis of a human melanoma cell line. Arch Dermatol Res 2000;292:482-7

Sandberg EM, Ma X, VonDerLinden D, Godeny MD, Sayeski PP. Jak2 tyrosine kinase mediates angiotensin II-dependent inactivation of ERK2 via induction of mitogen-activated protein kinase phosphatase 1. J Biol Chem 2004;279:1956-67

Snoeckx LH, Cornelussen RN, Van Nieuwenhoven FA, Reneman RS, Van Der Vusse GJ. Heat shock proteins and cardiovascular pathophysiology. Physiol Rev 2001;81:1461-97

Sugden $\mathrm{PH}$, Bogoyevitch MA. Intracellular signalling through protein kinases in the heart. Cardiovasc Res 1995;30:478-92
Sugden $\mathrm{PH}$, Clerk A. "Stress-responsive" mitogen-activated protein kinases (c-Jun N-terminal kinases and p38 mitogenactivated protein kinases) in the myocardium. Circ Res 1998;83:345-52

Suzuki E, Satonaka H, Nishimatsu H, Oba S, Takeda R, Omata M, Fujita T, Nagai R, Hirata Y. Myocyte enhancer factor 2 mediates vascular inflammation via the p38-dependent pathway. Circ Res 2004;95:42-9

Tojo A, Onozato ML, Kobayashi N, Goto A, Matsuoka H, Fujita T. Antioxidative effect of p38 mitogen-activated protein kinase inhibitor in the kidney of hypertensive rat. J Hypertens 2005; 23:165-74

Touyz RM, Deng LY, He G, Wu XH, Schiffrin EL. Angiotensin II stimulates DNA and protein synthesis in vascular smooth muscle cells from human arteries: role of extracellular signal-regulated kinases. J Hypertens 1999;17:907-16

Touyz RM, Schiffrin EL. Signal transduction mechanisms mediating the physiological and pathophysiological actions of angiotensin II in vascular smooth muscle cells. Pharmacol Rev 2000;52:639-72

Touyz RM, Berry C. Recent advances in angiotensin II signaling. Braz J Med Biol Res 2002;35:1001-15

Ushio-Fukai M, Alexander RW, Akers M, Griendling KK. p38 Mitogen-activated protein kinase is a critical component of the redox-sensitive signaling pathways activated by angiotensin II. Role in vascular smooth muscle cell hypertrophy. J Biol Chem 1998;273:15022-9

Wong HR, Dunsmore KE, Page K, Shanley TP. Heat shock-mediated regulation of MKP-1. Am J Physiol Cell Physiol 2005; 289:C1152-C8

Xu Q, Li DG, Holbrook NJ, Udelsman R. Acute hypertension induces heat-shock protein 70 gene expression in rat aorta. Circulation 1995;92:1223-9

Xu Q, Wick $\mathrm{G}$. The role of heat shock proteins in protection and pathophysiology of the arterial wall. Mol Med Today 1996;2: 372-9

Yoshizumi M, Tsuchiya K, Suzaki Y, Kirima K, Kyaw M, Moon $\mathrm{JH}$, Terao J, Tamaki T. Quercetin glucuronide prevents VSMC hypertrophy by angiotensin II via the inhibition of JNK and AP-1 signaling pathway. Biochem Biophys Res Commun 2002;293: 1458-65

Zheng Y, Song HJ, Kim CH, Kim HS, Kim EG, Sachinidis A, Ahn $\mathrm{HY}$. Inhibitory effect of epigallocatechin 3-O-gallate on vascular smooth muscle cell hypertrophy induced by angiotensin II. J Cardiovasc Pharmacol 2004;43:200-8 